\title{
Catheter-Based Management of Aortic Valve Regurgitation in Experimental Cardiology
}

\author{
J. ŠOCHMAN ${ }^{1,2}$, J. H. PEREGRIN ${ }^{2,3}$
}

${ }^{1}$ Clinic of Cardiology, Institute for Clinical and Experimental Medicine, ${ }^{2}$ Center for Cardiovascular Research, ${ }^{3}$ Department for Radiodiagnostic and Interventional Radiology, Prague, Czech Republic

Received February 21, 2007

Accepted March 7, 2007

On-line April 14, 2007

\begin{abstract}
Summary
Non-surgical management of aortic valve disease has been given considerable attention. Several recent publications have already reported its use in clinical practice. The main issue is to get an understanding of the pathophysiological processes and, most importantly, extensive experimental activity. In addition to testing various animal models, technical and material aspects are also being intensively investigated. It is not clear yet whether the durability and applicability of this promising development will be comparable with the standard of current cardiac surgery. Nonetheless, even the use of some models as a temporary approach helping to improve the circulatory status, not allowing safe surgery, is certainly justified. At any rate, a new stage of research and clinical application has been set off. However, experimental background continues to be simply indispensable. The paper is a short review of the issue.
\end{abstract}

\section{Key words}

Aortic valve regurgitation • Experimental research • Catheterization

\section{Corresponding author}

Jan Sochman, Clinic of Cardiology, IKEM, Videnska 1958/9, 146 22 Prague 4, Czech Republic. E-mail: jan.sochman@medicon.cz

\section{Elementary physiology and pathophysiology of the aortic valve}

The left ventricle generates a pressure under which a certain amount of blood is transported behind the aortic valve. Ideally, none of the expelled volume returns behind the valve. Trace regurgitation, demonstrable solely using auxiliary imaging techniques (e.g. by echocardiography) need not necessarily indicate, in the presence of an otherwise normal finding, a deviation from the physiological range. However, the transport of blood from the ventricle to the circulation does not occur completely unopposed. It is opposed by hydrostatic pressure from area situated at a level higher than the left ventricle and, most importantly, by resistance of the large vessels (whose elastic properties allow the shift of the pulse wave) and resistance of the vascular capacitance bed, which may additionally alter its own vasomotor characteristics thus significantly affecting the resistance. The resistance created in such a way generates a pressure shock, which passively closes the aortic orifice and provides rough information dealing with diastolic pressure. Under physiological conditions at the rest, the systolic/diastolic difference is not in excess of $100 \mathrm{~mm} \mathrm{Hg}$. Aortic valve disease may be either due to orifice narrowing or due to a loss of functional valve closure. In the former case, pressure-type of heart failure with respect to the prolonged period of time sets in with a component of relatively long-lasting compensatory mechanisms. In the latter case, the compensatory process is made shorter by the component of left ventricular hypertrophy, with the volume type of heart failure possibly developing in the future. There are situations when both impairments combine. Likewise, there are conditions when aortic valve disease develops quickly or, more often, when all factors of physiological compensation are suddenly exhausted. In these cases a radical management is considered. While the cardiac surgery is a current therapeutic standard, catheterization- 
based approaches have been proposed. However, these approaches continue to be essentially derived from experimental techniques. This text is a brief overview of the development of experimental methods modulating aortic valve disease, and aortic regurgitation in particular. At the same time, it is critical to balance neatly between views perceiving catheter-based approaches as definitive therapy and approaches, which are only transient. Definitive catheter-based management of aortic insufficiency has not been completely defined. One cannot simply copy the situation seen during pulmonary artery valve disease. Current catheter-based techniques are only applicable in cases whereby surgical management is not safe for a given situation. Once hemodynamic status has improved as a result of the catheter-based approach, it is possible to consider a a definitive surgical solution proven by the current therapy.

\section{Historical overview}

The effort over the past 40 years at creating a catheter-based cardiac valve replacement has evolved from experimental work to initial clinical application. Initially, these attempts were aimed at managing valve diseases in tubular structures such as the pulmonary artery or the aorta. The idea was to provide temporary support to the failing myocardium and to reduce the impact of heart failure on organs so that possible improvement could be followed by a definitive surgical treatment. Clearly, there has been a parallel effort to manage the valve problem not temporarily, but permanently using a direct catheter-based approach. With regards to valve regurgitation, the issue is not homogenous. One option of management is focused on techniques modifying the orifice per se and the second approach is represented by valve-replacing techniques. Very often, the procedures require the close cooperation of an interventionalist with the surgeon. The text below examines some techniques employed in the presence of valve regurgitation as related to their basic shape structure and experimental data as well as technical valve designs and the overall philosophy governing their use. We are undoubtedly at the start of new techniques where only the future will show how successful are these steps. The use of a catheter-based techniques is logically justified only in cases where it is necessary to bridge a period to safe surgery (provisional catheter-based treatment) or in cases where current catheter-based techniques have been shown to be effective and durable for a period comparable with that of surgery (i.e., roughly more than five years). Experimental background is still essential.

\section{Aortic valve parameters}

Aortic valve is an integral part of aorta with tubular-like structure. The valve apparatus consists of three well-defined leaflets with definitive passive motion during systole and diastole. Due to relatively high systolic and diastolic pressure the aortic valve is confronted with a relatively high mechanical stress and, in terms of morphology, a consideration is to be made of the relation to origin of the coronary arteries. The movement of the tube during systole and diastole is very limited in all directions. Most of all useful parameters is derived from echocardiography followed by MR imaging or contrast aortography. Here again, the key considerations are the diameters of the aortic valve orifice and of the adjoining segment of the ascending aorta.

\section{Aortic valve regurgitation}

Experimental attempts and proposed designs seeking reduction or a complete elimination of aortic regurgitation date back more than four decades ago. Initial studies were based on the fact verified surgically that the valve can also be placed in a supra-coronary position (Hufnagel and Harvey 1953, Hufnagel et al. 1954, Harken et al. 1960). Optional positions of the aortic prosthesis placed using a catheter-based procedure could be described in relation to virtual line of leaflet coaptation. The choice is as follows: supracoronary and infracoronary, orthotopic or heterotopic.

\section{Experimental models}

All initial designs used the mechanical components. The pioneering work apparently dates back to Davies (1965) providing a temporary solution of aortic regurgitation. This was followed by a number of proposed techniques, all essentially a modification of the original idea whereby a catheter is temporarily advanced to the aortic region and its modification should reduce or, ideally, completely stop the regurgitating blood flow (Moulopoulos et al. 1971, Moulopoulos 1972, Philips et al. 1976, Boretos and Poirier 1977, Matsubara et al. 1992). The specific idea was to use the intraaortic balloon pump with timing different from that used conventionally 


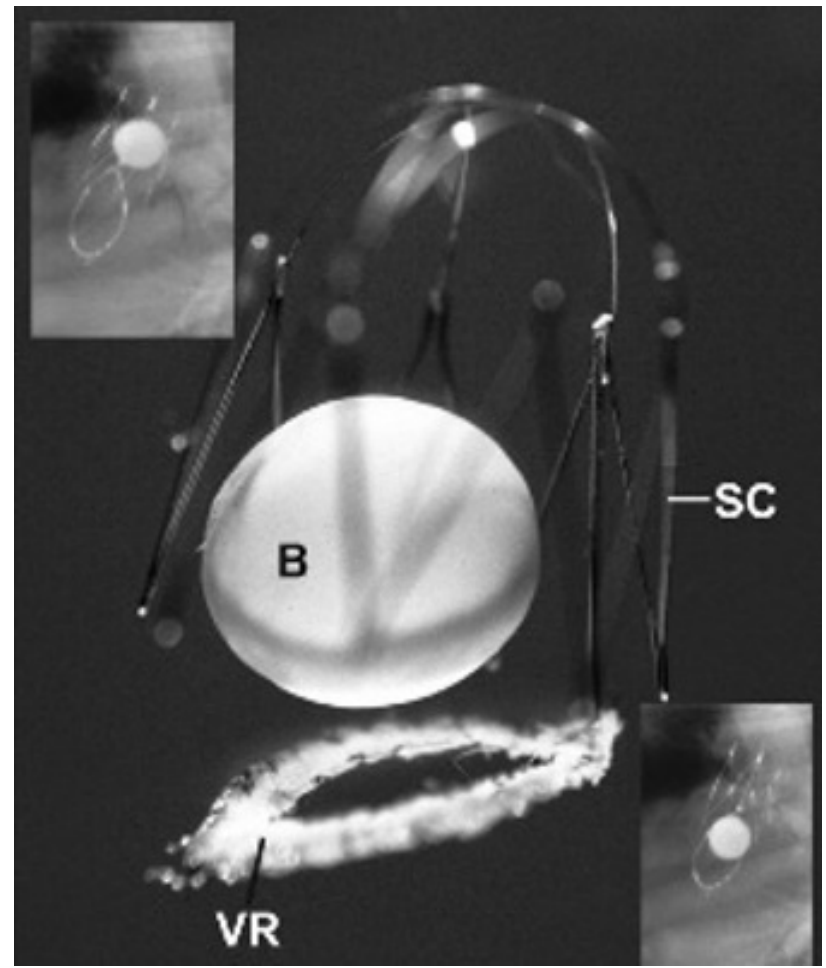

Fig. 1. Ball and cage design for catheter-based aortic valve prosthesis deployment. SC - Gianturco-Rösch Z stent carrier, B ball, VR - valve ring for the new orifice. Left upper corner: scene from cinefluorography in systole, right lower corner: in diastole.

(Moulopoulos et al. 1980). A completely revolutionizing approach was published by Pavcnik et al. (1992), fully eliminating the previously advanced catheter as an anchoring mechanism. The new design remotely resembled a stent at one end and the cage of a surgically used ball mechanical prosthesis at the other. The whole prosthesis was implanted in two steps: first, the actual cage carrier and second, a detachable balloon filled with a fluid with an admixture of a contrast medium (Fig. 1).

This was followed by a series of investigations, which already divided the next approaches to a purely mechanical prostheses implanted using a catheter, bioprostheses implanted using the same technique, and hybrid approaches. In our department, we tested the purely mechanical prostheses in a two-stage experiment, with the stent carrier inserted first and followed by valve disc placement (Šochman et al. 2000) (Fig. 2).

This was already an imitation of the model of disc prosthesis proven by surgical practice. From a family of catheter-implantable bioprostheses as well as from a historical overview, some approaches affecting clinical practice could be quoted (Andersen et al. 1992, Moazami et al. 1996, Boudjemline et al. 2002, Boudjemline and Bonhoeffer 2002a,b, 2003, Lutter et al. 2002, Huber et al.

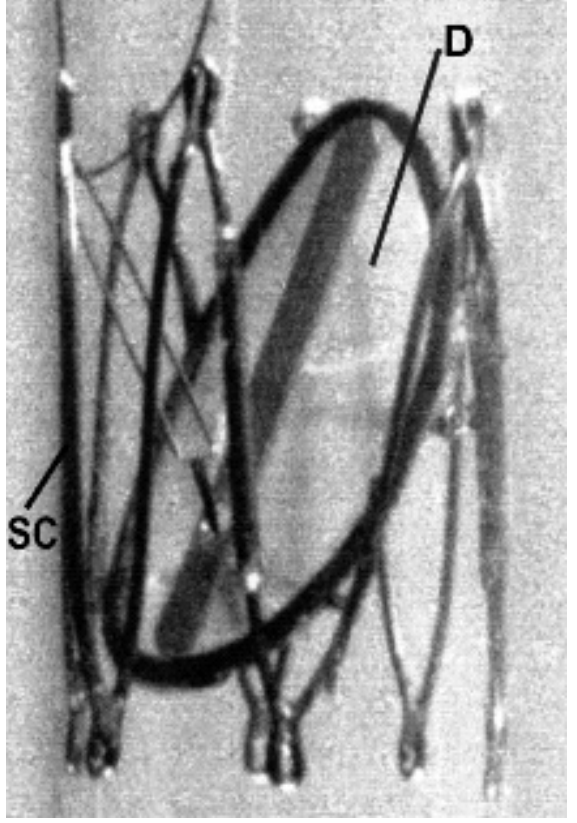

Fig. 2. Mechanical disc valve design for two-step deployment. SC - stent carrier (deployed in the first step), D - disc (deployed and locked in the second step)

2004). While the advantage of this model was prosthesis implantation at the time, its drawback was a relatively bigger caliber of the instrumentarium. The above techniques made use of a stent carrier, which had to be dilated during deployment by a balloon catheter. However, there are designs using a self-expandable carrier with an anchored biological valve (Ferrari et al. 2004). Besides, hybrids have been developed which, while seeking to resemble, in their design, the shape of the native valve, made use of plastic membranes of most varied properties (Hilbert et al. 1987, Lo et al. 1988). Currently, a new option is being tested experimentally whereby the membrane component of the valve is not made of plastic or conventional biological material (pericardium, homogenized animal valve, etc.). Instead, the material used is small intestinal submucosa (Pavcnik et al. 2001). Because of material duration and biodegradability characteristics, the research has again focused on an area showing less demands on mechanical stress (Ruiz et al. 2005). Presently, the bioprosthetic models clearly predominate. Their advantages includes the orthotopic position (i.e., infracoronary and valvular with respect to the annular position). However, mechanical prostheses, which are used less often, have improved in being capable of being established at the time, as is the case of bioprostheses (Šochman et al. 2006). However, their position is supracoronary (i.e. supra-valvular in relation to the annulus) (Fig. 3). 


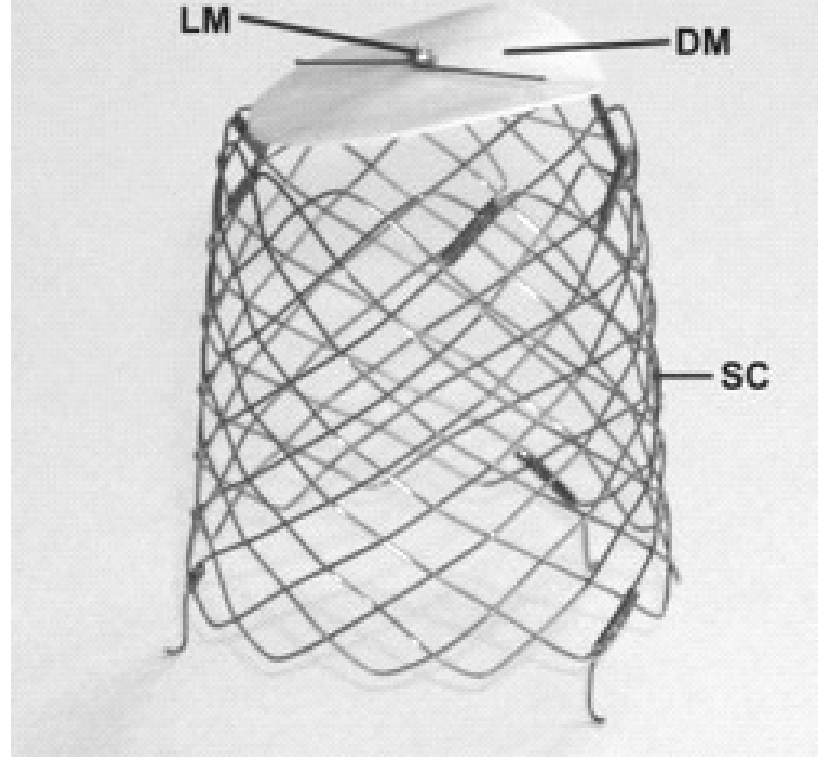

Fig. 3. Mechanical disc valve design for one-step deployment. SC - SX braided stent carrier, DM - flexible disc membrane, LM locking mechanism

We are currently testing a completely different position of mechanical prosthesis, i.e. infracoronary and infravalvular. First experiments were encouraging (Fig. 4).

\section{Purely catheter-based options in clinic application}

Recently, some papers have reported a catheterbased therapy also in man. Quite surprisingly, the problem was not aortic regurgitation but aortic stenosis in the group of so-called "no-option treatment" patients. These patients were not indicated for surgical therapy because it was considered too risky; moreover, they were of advanced age. In addition, aortic balloon valvuloplasty, as previously considered, was no longer concerned. In this particular case, a stent carrier with a biological valve was introduced into the aortic orifice, with the stent carrier pushed into the aortic wall using the balloon in orthotopic position. Initial results are said to be most encouraging (Cribier et al. 2002, 2004, Bauer et al. 2004, Hanzel et al. 2005, Grube et al. 2005). Still, nothing is known about the durability of the above measure.

\section{Potential role for catheter-based managements}

There is no doubt that the key method for

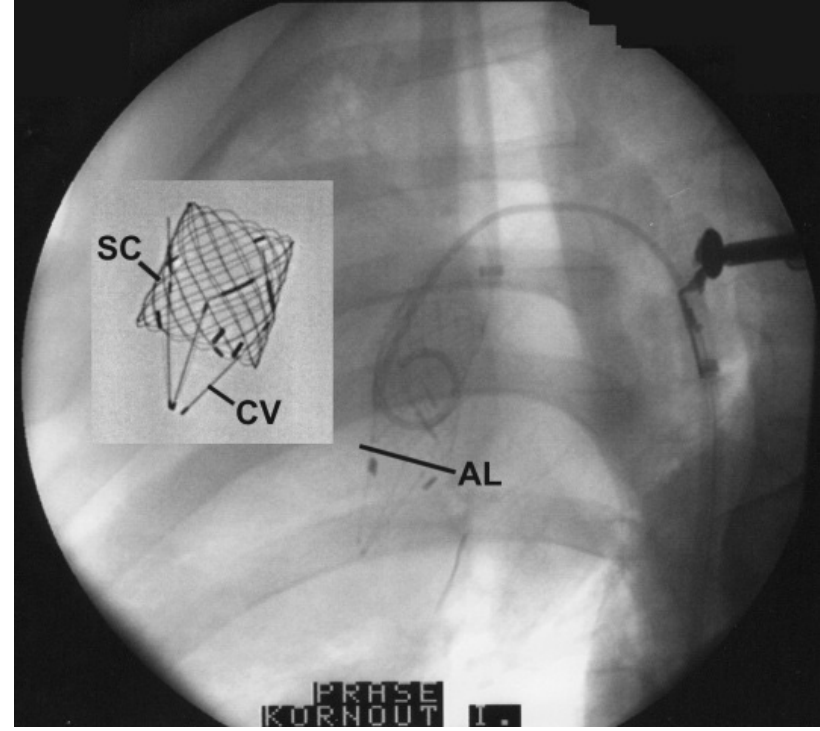

Fig. 4. Mechanical cone valve design for infracoronary positioning. X-ray picture: SC - stent carrier, CV - cone valve struts. A pig model: AL - annular level (left ventricular outflow tract is below the line!)

managing any valve disease is surgery. This is supported by time-proven clinical practice, declared outcomes and undisputed durability. However, the era of catheter-based therapy has begun: in some centers, it is most successful option, in other centers, it has not moved beyond the experimental stage. In some centers, it is the object of skepticism, critique or concern. However, if it does handle a temporary problem making safe surgery unfeasible, it should be accepted. This applies in particular to acute and life-threatening states. Logically, one should conclude that a biological prosthesis is not the only solution. In non-acute cases, other logical requirements are to be met in addition to the clear-cut requirement ruling out "major surgery". These requirements include reliability and feasibility in an acceptable form and, most importantly, outcome durability. However, only the future will tell. At any rate, there will be no progress without experimental work.

\section{Conflict of Interest}

There is no conflict of interest.

\section{Acknowledgements}

This work was supported by the Institute for Clinical and Experimental Medicine (research project Nr. \# 00023001 granted by the Ministry of Health) as well as by research grant awarded by Ministry of Education, Youth and Sports (registration Nr. \# 1M6798582302). Figure 1 was supplied with a courtesy by D. Pavcnik. 


\section{References}

ANDERSEN HR, KNUDSEN LL, HASENKAM JM: Transluminal implantation of artificial heart valves: description of a new expandable aortic valve and initial results with implantation by catheter technique in closed chest pig. Eur Heart J 13: 704-708, 1992.

BAUER F, ELTCHANINOFF H, TRON CH, LESSAULT PF, AGATIELLO C, NERCOLINI D, DERUMEAUX G, CRIBIER A: Acute improvement in global and regional left ventricular systolic function after percutaneous heart valve implantation in patients with symptomatic aortic stenosis. Circulation 110: 473-476, 2004.

BORETOS JW, POIRIER RA: Aortic valve catheter. United States Patent Nr. 4056 854, 1977.

BOUDJEMLINE Y, BONHOEFFER P: Percutaneous implantation of a valve in the descending aorta in lambs. Eur Heart J 23: 1045-1049, 2002a.

BOUDJEMLINE Y, BONHOEFFER P: Steps towards percutaneous aortic valve replacement. Circulation 105: 775 778, 2002b.

BOUDJEMLINE Y, BONHOEFFER P: Percutaneous valve insertion: a new approach? J Thorac Cardiovasc Surg 125 : 741-742, 2003.

BOUDJEMLINE Y, BONNET D, SIDI D, BONHOEFFER P: Percutaneous implantation of a biological valve in the aorta to treat aortic valve insufficiency - a sheep study. Med Sci Monit 8: BR113-116, 2002.

CRIBIER A, ELTCHANINOFF H, BASH A, BORENSTEIN N, TRON C, BAUER F, DERUMEAUX G, ANSELME F, LABORDE F, LEON MB: Percutaneous transcatheter implantation of an aortic valve prosthesis for calcified aortic stenosis. First human case description. Circulation 106: 3006-3008, 2002.

CRIBIER A, ELTCHANINOFF H, TRON CH, BAUER F, AGATIELLO C, SEBAGH L, BASH A, NUSIMOVICI D, LITZLER PY, BESSOU JP, LEON MB: Early experience with percutaneous implantation of heart valve prosthesis for the treatment of end-stage inoperable patients with calcific aortic stenosis. J Am Coll Cardiol 43: 698-703, 2004.

DAVIES H: Catheter-mounted valve for temporary relief of aortic insufficiency. Lancet I: 250, 1965.

FERRARI M, FIGULLA HR, SCHLOSSER M, TENNER I, FRERICHS I, DAMM C, GUYENOT V, WERNER GS, HELLIGE G: Transarterial aortic valve replacement with a selfexpanding stent in pigs. Heart 90: 1326-1331, 2004.

GRUBE E, LABORDE JC, ZICKMANN B, GERCKENS U, FELDERHOFF T, SAUREN B, BOOTSVELD A, BUELLESFELD L, IVERSEN S: First report on a human percutaneous transluminal implantation of a selfexpanding valve prosthesis for interventional treatment of aortic valve stenosis. Cathet Cardiovasc Interv 66: 465-469, 2005.

HANZEL GS, HARRITY PJ, SCHREIBER TL, O'NEILL WW: Retrograde percutaneous aortic valve implantation for critical aortic stenosis. Cathet Cardiovasc Interv 64: 322-326, 2005.

HARKEN DE, SOROFF HS, TAILOR WJ, LEFEMINE AA, GUPTA SK, LUNZER S: Partial and complete prosthesis in aorta insufficiency. $J$ Thorac Cardiovasc Surg 40:744-762, 1960.

HILBERT SL, FERRANS VJ, TOMITA Y, EIDBO EE, JONES M: Evaluation of explanted polyuretane trileaflet cardiac valve prostheses. J Thorac Cardiovasc Surg 94: 419-429, 1987.

HUBER CH, TOZZI P, CORNO AF, MARTY B, RUCHAT P, GERSBACH P, NASRATULLA M, VON SEGESSER LK: Do valve stents compromise coronary flow? Eur J Cardio-thorac Surg 25: 754-759, 2004.

HUFNAGEL CA, HARVEY WP: The surgical correction of aortic regurgitation: preliminary report. Bull Georgetown Univ Med Ctr 6: 3-6, 1953.

HUFNAGEL CA, HARVEY WP, RABIL PJ, MCDERMOT TF: Surgical correction of aortic insufficiency. Surgery 35: 673-683,1954.

LO HB, HEROLD M, REUL H, MUCKTER H, TAGUCHI K, SURMANN M, HILDINGER KH, LAMBERTZ H, DE HAAN H, HANDT S: A tricuspid polyuretane heart valve as an alternative to mechanical protheses or bioprostheses. ASAIO Trans 34: 839-844, 1988.

LUTTER G, KUKLINSKI D, BERG G, VON SAMSON P, MARTIN J, HANDKE M, UHRMEISTER P, BEYERSDORF F: Percutaneous aortic valve replacement: an experimental study.I. Studies on implantation. J Thorac Cardiovasc Surg 123: 768-776, 2002. 
MATSUBARA T, YAMAZOE M, TAMURA Y, OHSHIMA M, YAMAZAKI Y, SUZUKI M, IZUMI T, SHIBATA A: Balloon catheter with check valves for experimental relief of acute aortic regurgitation. Am Heart $J$ 124: 1002-1008, 1992.

MOAZAMI N, BESSLER M, ARGENZIANO M, CHOUDHRI, AF, CABRERIZA SE, ALLENDORF JD, ROSE EA, OZ MC: Transluminal aortic valve placement: a feasibility study with a new designed collapsible aortic valve. ASAIO J 42: M381-M385, 1996.

MOULOPOULOS S: Catheter-mounted artificial heart valve for implanting in close proximity to a defective natural heart valve. United States Patent: Nr. 3672 979, 1972.

MOULOPOULOS S, ANTHOPOULOS L, STAMATELOPOULOS S, STEFADOUROS M: Catheter-mounted aortic valves. Ann Thorac Surg 11: 423-430, 1971.

MOULOPOULOS SD, ANTHOPOULOS LP, ANTONATOS PG, ADAMOPOULOS PN, NANAS JN: Intra-aortic balloon pump for relief of aortic regurgitation: experimental study. J Thorac Cardiovasc Surg 80: 38-44, 1980.

PAVCNIK D, WRIGHT KC, WALLACE S: Development and initial experimental evaluation of a prosthetic aortic valve for transcatheter placement. Radiology 183: 151-154, 1992.

PAVCNIK D, UCHIDA B, TIMMERMANS H, KELLER FS, RÖSCH J: Square stent: a new self expandable endoluminal device and its application. Cardiovasc Intervent Radiol 24: 207-217, 2001.

PHILIPS SJ, CIBORSKI M, FREED PS, CASCADE PN, JARON D: A temporary catheter-tip aortic valve: hemodynamic effects on experimental acute aortic insufficiency. Ann Thorac Surg 21: 134-137, 1976.

RUIZ CE, IEMURA M, MEDIE S, VARGA P, VAN ALSTINE WG, MACK S, DELIGIO A, FEARNOT N, BEIER VH, PAVCNIK D, HIJAZI ZM, KIUPEL M: Transcatheter placement of a low-profile biodegradable pulmonary valve made of small intestine submucosa: a long-term study in a swine model. J Thorac Cardiovasc Surg 130: 477-484, 2005.

ŠOCHMAN J, PEREGRIN JH, PAVCNIK D, TIMMERMANS H, RÖSCH J: Percutaneous transcatheter aortic disc valve prosthesis implantation: a feasibility study. Cardiovasc Intervent Radiol 23: 384-388, 2000.

ŠOCHMAN J, PEREGRIN JH, ROCEK M, TIMMERMANS HA, PAVCNIK D, RÖSCH J: Percutaneous one-step mechanical aortic disc prosthesis implantation: a preliminary feasibility study in swine. Cardiovasc Intervent Radiol 29: 1149, 2006. 